Federal Reserve Bank of Minneapolis

Research Department Staff Report 252

August 1998

\title{
The Existence of Rational Expectations Equilibrium: A Retrospective
}

\author{
Beth Allen* \\ Federal Reserve Bank of Minneapolis \\ and University of Minnesota
}

James S. Jordan*

University of Minnesota

\begin{abstract}
This paper provides a selective review of theoretical research on the consistency of rational expectations equilibrium and its properties in microeconomic models. The general equilibrium framework is emphasized throughout the paper. After defining rational expectations equilibrium for a pure exchange economy, the paper presents a simple counterexample to illustrate that rational expectations equilibria need not exist. Results are summarized for the generic existence of fully revealing rational expectations equilibria in smooth economies satisfying additional dimensionality assumptions. Then the rational expectations equilibrium existence problem is related to earlier analysis of informationally decentralized allocation mechanisms. Next the efficiency properties of rational expectations equilibrium allocations are examined. Finally, the possibilities for partially revealing rational expectations equilibria are discussed.

*Preparation of this manuscript was supported by NSF Grants SBR-9309854 and IRI 9312783. Previous financial support from the National Science Foundation for much of the research described here is also gratefully acknowledged. The views expressed herein are those of the authors and not necessarily those of the Federal Reserve Bank of Minneapolis or the Federal Reserve System.
\end{abstract}




\section{Introduction}

The term rational expectations is introduced in the famous article of Muth (1961), but the equilibrium existence problem posed by such a concept had been recognized and addressed formally seven years earlier. Grunberg and Modigliani (1954) recognize that predictions of economic events, unlike weather forecasts, can affect predicted events. Expectations of a substantial price increase, for example, can trigger investment and production decisions that increase supply and cause the actual price increase to be smaller than expected. While weather forecasting may be difficult in practice, even the logical possibility of economic forecasting is problematic. Although they did not model the process of price determination explicitly, Grunberg and Modigliani show that Brouwer's fixed point theorem implies the existence of a correct forecast, provided that the requisite continuity and boundary conditions are satisfied. Muth (1961) acknowledges the Grunberg and Modigliani article but focuses more on using the assumption of rational expectations to specify expectations in econometric models in which the equilibrium could be obtained by construction.

The dramatic advances in the mathematical theory of general equilibrium during the fifties and early sixties stimulated efforts to include expectations and uncertainty in general equilibrium models during the late sixties and early seventies. Two articles by Radner $(1968,1972)$ stand out from the many notable contributions of this period for their explicit focus on the information structure underlying the formation of expectations. Radner's models impose the strong informational consistency requirement that an agent's actions could not differ across states of the world that could not be distinguished by the agent's information. This condition restricts trade among agents to events that are mutually observable. As Radner emphasizes, "the net trade between any group of agents and the group of all other agents in the economy can at most depend upon information that is common to both groups of agents." [Radner (1968, p. 50, italics in orig- 
inal)]. As a result, Radner's existence theorems rely on the assumption that all agents are endowed with a common information structure. The possibility that information revealed by prices might remove incongruities in initial information is not pursued. In an earlier unpublished technical report, Radner (1967) had explicitly added the information revealed by prices to agents' information structures. However, the discussion of the existence of equilibrium is confined to the prophetic remark: "It is not clear that an equilibrium of the type defined above exists, even under the classical assumptions. The continuity of the demand functions can, in principle, be destroyed by the fact that information depends on the structure of spot prices..."

The first positive and negative results on price-conditional rational expectations equilibrium were both achieved by Jerry Green (1973, 1977). Green (1973) describes a market for the exchange of state-contingent wealth claims in which some traders are privately informed of the "true" state probabilities, while other traders have no private information. Green (1973) shows that the traders' excess demand functions, when differentiated with respect to the state probabilities, have a dominant diagonal property that implies that the function from state probabilities to market-clearing prices is oneto-one. Hence, there exists in this model a rational expectations equilibrium in which market prices fully reveal the state probabilities to the uninformed traders. Grossman (1981) and Handel (1980) later show that the key property of contingent claim demand is sufficiently general that the differentiability of demand functions is unnecessary for the result. However, Green [1975, later published as Green (1977)] shows that the absence of "noise" in the model is essential, not only for the full revelation property, but even for the existence of equilibrium. More specifically, Green (1973) constructs an example in which traders' endowments are subject to state-independent random noise and shows that the example admits no rational expectations equilibrium. 
The contingent claims market setting of Green's (1973) counterexample made the example necessarily complex. Subsequent authors, notably Kreps (1977), discovered much simpler examples of the nonexistence of equilibrium in spot market models. One such example is described in the next section. Thus, while the causal influence of economic expectations that trouble Grunberg and Modigliani (1954) can be resolved, as they suggest, by conventional fixed point methods, the informational discontinuity discovered by Radner (1967) can be fatal to the existence of rational expectations equilibrium even under classical assumptions on trader characteristics.

What follows is an exposition and review of selected aspects of the rational expectations equilibrium existence problem and its literature. We make no pretense of completeness but refer the reader to Radner (1982) for additional references and topics. Section 2 defines the conventional concept of rational expectations equilibrium (REE), and Section 3 contains a simple example in which the equilibrium fails to exist. Section 3 also reviews the literature on the generic existence of REE. Section 4 relates the existence problem to an earlier model of informationally decentralized allocation mechanisms and demonstrates the general existence of equilibrium when expectations are conditioned on trades as well as prices. Sections 5 and 6 contain brief discussions of the efficiency of REE and the existence of partially revealing REE, respectively.

\section{Rational Expectations Equilibrium}

There are $n$ traders, indexed by the superscript $i$, and $\ell$ commodities, indexed by subscripts. Each trader $i$ has a set $S^{i}$ of private information signals, where $S^{i}$ is a finite-dimensional Euclidean space. Let $S=\Pi_{i=1}^{n} S^{i}$, with generic element $s=$ $\left(s^{1}, \ldots, s^{n}\right)$. An element $s \in S$ is termed a state of information. Let $\pi$ denote a Borel probability measure on $S$. 
Let $U$ denote the set of smooth (infinitely continuously differentiable) functions $u: \mathbb{R}_{++}^{\ell} \rightarrow \mathbb{R}$ satisfying, for each $x \in \mathbb{R}_{++}^{\ell}$,

i) $D u^{i}(x) \in \mathbb{R}_{++}^{\ell}$,

ii) $D^{2} u^{i}(x)$ is negative definite, and

iii) the closure in $\mathbb{R}^{\ell}$ of the upper contour set $\left\{x^{\prime} \in \mathbb{R}_{++}^{\ell}: u\left(x^{\prime}\right) \geq u(x)\right\}$ is contained in $\mathbb{R}_{++}^{\ell}$.

The set $U$ is topologized as a subspace of $C^{\infty}\left(\mathbb{R}_{++}^{\ell}, \mathbb{R}\right)$ with the $C^{\infty}$ compact-open topology. ${ }^{1}$ Each trader $i$ has a state-dependent utility function $v^{i}: S \rightarrow U$ which is Borel-measurable. The tactic of representing the utility function as a random variable, as opposed to viewing the utility of each commodity bundle as a separate random variable, is taken from Allen (1981a). It avoids a technical problem in the definition of conditional expected utility maximization noted by Kreps (1977). ${ }^{2}$ In general, each trader $i$ 's endowment can also be state-dependent (but measurable with respect to $s^{i}$ ). However, in this exposition, we will adopt the common simplifying assumption that each trader $i$ has a state-independent endowment $e^{i} \in \mathbb{R}_{++}^{\ell}$.

Let $\Delta$ denote the unit simplex in $\mathbb{R}_{+}^{\ell}$, and let $M=\left\{\left(p, y^{1}, \ldots, y^{n}\right) \in \Delta \times \mathbb{R}^{n \ell}\right.$ : $\sum_{i=1}^{n} y^{i}=0$ and $\quad p y^{i}=0$ for each $\left.i\right\}$ denote the set of prices and $n$-tuples of net trades that satisfy the aggregate resource balance and individual budget constraints. A rational expectations equilibrium (REE) will take the form of a Borel-measurable function from $S$ to $M$. The space $M$ contains the market signals that traders can use to augment the information provided by their private signals.

In a rational expectations equilibrium, the information available to trader $i$ will be at least $s^{i}$ and at most the entire state $s$ of information. It will be useful to define equilibria corresponding to the two extremes. A private information equilibrium (PIE) 
is a Borel-measurable function $\left(\tilde{p}(\cdot),\left(\tilde{y}^{i}(\cdot)\right)_{i}\right): S \rightarrow M$ satisfying, for each $i$,

$$
\tilde{y}^{i}(s) \text { maximizes } E\left\{v^{i} \mid s^{i}\right\}\left(e^{i}+y^{i}\right)
$$

subject to $\tilde{p}(s) y^{i}=0, \quad$ for almost every $s$,

where $E\left\{v^{i} \mid s^{i}\right\} \in U$ is the conditional expectation of $v^{i}$ given the $\sigma$-field generated by the projection $s \mapsto s^{i}$. A full communication equilibrium (FCE) is a Borelmeasurable function $\left(\tilde{p}(\cdot),\left(\tilde{y}^{i}(\cdot)\right)_{i}\right): S \rightarrow M$ satisfying, for each $i$,

$$
\begin{aligned}
& \tilde{y}^{i}(s) \quad \text { maximizes } v^{i}(s)\left(e^{i}+y^{i}\right) \\
& \text { subject to } \tilde{p}(s) y^{i}=0, \quad \text { for almost every } s .
\end{aligned}
$$

In the conventional definition of rational expectations equilibrium, traders augment their private signals with the information revealed by market prices. Formally, a rational expectations equilibrium (REE), is a Borel-measurable function $\left(\tilde{p}(\cdot),\left(\tilde{y}^{i}(\cdot)\right)_{i}\right): S \rightarrow M$ satisfying, for each $i$,

$$
\begin{aligned}
& \tilde{y}^{i}(s) \text { maximizes } E\left\{v^{i} \mid s^{i}, \tilde{p}(s)\right\}\left(e^{i}+y^{i}\right) \\
& \text { subject to } \tilde{p}(s) y^{i}=0, \quad \text { for almost every } s .
\end{aligned}
$$

\section{Existence and Nonexistence of REE}

The earliest simple example of the nonexistence of REE is given by Kreps (1977). In this example, there are only two possible states. Since there are only two states, if prices differ between the states then an REE must be an FCE, while if prices are the same in the two states, an REE must be a PIE. Nonexistence of REE is proved by showing that in the unique FCE, the prices are the same in the two states, and in the unique PIE, the prices differ between the two states. 
Formally, consider a variant of the counterexample that appears in Allen (1984). Suppose there are two traders and two commodities, and suppose that the support of the probability measure $\pi$ on traders' signals consists of the two-point set $\left\{\left(s_{a}^{1}, s^{2}\right),\left(s_{b}^{1}, s^{2}\right)\right\}$, where $s_{a}^{1} \neq s_{b}^{1}$, and the two states have equal probability. Thus trader 1 is privately fully informed of the state, while the private signal of trader 2 does not reveal the state. Let $s_{a}=\left(s_{a}^{1}, s^{2}\right)$ and $s_{b}=\left(s_{b}^{1}, s^{2}\right)$, and define $v^{1}$ and $v^{2}$ on these states by the following:

$$
\begin{aligned}
& v^{1}\left(s_{a}\right)(x)=2 \ln x_{1}+\ln x_{2}, \\
& v^{1}\left(s_{b}\right)(x)=\ln x_{1}+2 \ln x_{2}, \\
& v^{2}\left(s_{a}\right)(x)=\ln x_{1}+2 \ln x_{2}, \\
& v^{2}\left(s_{b}\right)(x)=2 \ln x_{1}+\ln x_{2} .
\end{aligned}
$$

The state-independent endowments are $e^{1}=e^{2}=(3,3)$. Then the unique FCE satisfies $\tilde{p}\left(s_{a}\right)=\tilde{p}\left(s_{b}\right)=(1 / 2,1 / 2)$, while $\tilde{y}^{1}\left(s_{a}\right)=(1,-1), \quad \tilde{y}^{1}\left(s_{b}\right)=(-1,1)$, and $\tilde{y}^{2}(\cdot)=-\tilde{y}^{1}(\cdot)$. Since $\tilde{p}\left(s_{a}\right)=\tilde{p}\left(s_{b}\right)$, the FCE cannot be an REE. In a PIE, trader 2 is uninformed of the state; for any given price, trader 2 will have the same demand in both states. It is also clear (from the definition of $v^{1}$ and the fact that trader 1 is privately informed of the state) that, for any given price, trader 1 will demand more of commodity 1 in state $s_{a}$ than in state $s_{b}$. Thus no PIE can have the same prices in both states; in fact, the unique PIE has $\tilde{p}\left(s_{a}\right)=(7 / 12,5 / 12)$ and $\tilde{p}\left(s_{b}\right)=$ $(5 / 12,7 / 12)$. Hence there is no rational expectations equilibrium for this economy.

Radner (1979) also develops an example with log-linear utility functions. However, in his framework, information signals concern traders' conditional probabilities of various events, while the relationships between states of the world and agents' preferences are considered fixed. We find it simpler to identify signals and states of the world, thereby replacing Radner's (1979) conditional probabilities by zeros and ones. As in 
Allen (1981a, 1984), we consider a space of economies that is defined by state-dependent preferences. By contrast, Radner's (1979) model fixes the state-dependent preferences and then specifies various economies by their collections of conditional probabilities.

Radner (1979) shows that the property that prevents an FCE from being an REE in such examples is nongeneric in the space of arrays of conditional probabilities of states of the world given agents' signals. Radner's result is stated in the context of financial asset markets, but the essential idea is easily expressed in the present model. For each state of information $s$, the economy $\left(e^{i}, v^{i}(s)(\cdot)\right)_{i=1}^{n}$ is a smooth economy as defined by Debreu (1972). Suppose that the support of $\pi$ is a finite set $S^{o}=\left\{s_{k}\right\}_{k=1}^{K}$. Then an FCE consists simply of a Walrasian equilibrium $\left(\tilde{p}\left(s_{k}\right),\left(\tilde{y}^{i}\left(s_{k}\right)\right)_{i}\right)$ for the economy $\left(e^{i}, v^{i}\left(s_{k}\right)(\cdot)\right)_{i}$, for each $k$. If $\tilde{p}(\cdot)$ is one-to-one, then the FCE is an REE as well. The contrary condition that $\tilde{p}\left(s_{k}\right)=\tilde{p}\left(s_{k^{\prime}}\right)$ for some $k$ and $k^{\prime}$ is a "knife-edge" property that Radner shows is nongeneric in the smooth economies $\left\{\left(e^{i}, v^{i}\left(s_{k}\right)(\cdot)\right)_{i}\right\}_{k=1}^{K}$ parameterized as described above. A formal statement and proof of the analogue of this result for the present model is given by Allen (1984).

Allen (1981a, 1982b) shows that the generic existence of fully revealing rational expectations equilibria extends well beyond the class of economies considered by Radner (1979). While Radner's analysis relies heavily on the finiteness of the set of possible states of information, Allen (1981a, 1982b) shows that the essential condition is merely that the price space have a higher dimension than the state space. Allen (1981a) establishes that if $\operatorname{dim} S<(1 / 2) \operatorname{dim} \Delta$, then an FCE price function $\tilde{p}(\cdot)$ is generically one-to-one. Moreover, Allen (1982b) shows that if $\operatorname{dim} S<\operatorname{dim} \Delta$, an FCE price function is generically one-to-one on the complement of a subset of $S$ having Lebesgue measure zero. In particular, if $\pi$ is absolutely continuous with respect to Lebesgue measure, an FCE price function is generically one-to-one on a set having probability one and is thus generically an REE. The first result relies on the Whitney Embed- 
ding Theorem from differential topology, while the second uses the related ideas of selfintersections of immersed manifolds (based on multijet transversality).

Stimulated by Allen's (1981a, 1982b) results, Jordan and Radner (1979, 1982) consider the equal dimension case, that is, $\operatorname{dim} S=\operatorname{dim} \Delta$. They show via an example that in this case, neither the existence nor the nonexistence of an REE is a generic property. This leaves the higher dimensional case, $\operatorname{dim} S>\operatorname{dim} \Delta$. In this case, an FCE generically cannot be an REE, since an FCE price function $\tilde{p}$ generically is smooth enough that it cannot map $S$ to a lower dimensional space and still be one-to-one on a subset of $S$ with full Lebesgue measure. However, Jordan (1982a) demonstrates the generic existence of REE price functions $\tilde{p}$ that are two-to-one. Moreover, the price functions $\tilde{p}$ can be made arbitrarily close to one-to-one in the sense that the pairs of states mapped to the same price can be made uniformly arbitrarily close to one another. In particular, there are many such equilibria. However, the constructed price functions are discontinuous on a dense subset of $S$ so that one would hesitate to interpret such equilibria as the natural outcome of a market mechanism. Thus, in the higher dimensional case, the generic existence of economically plausible rational expectations equilibria remains an open question.

\section{Generalized Rational Expectations Equilibrium}

In the conventional definition of rational expectations equilibrium, prices are the only market variables that traders use to augment their private information. This accords with the usual interpretation of prices as the coordinating signals that enable the competitive market to achieve Pareto optimal allocations. Indeed, Grossman (1981) argues that the existence of a fully revealing REE is the appropriate formalization of Hayek's (1945) famous assertion that the market mechanism is informationally efficient. This interpretation suggests that the informational discontinuity discovered by Radner 
(1967) constitutes a serious flaw in the market mechanism that may preclude the possibility of informationally efficient price systems. However, there is a prior line of research on Hayek's conjecture that suggests that the sole reliance on price constitutes a misunderstanding of the market mechanism.

Hurwicz (1977) and Mount and Reiter (1974) construct an explicit model of competitive equilibrium as an informationally decentralized allocation mechanism. In their model, the market signal, which these authors call the "competitive message," is the entire list of market variables, $\left(p,\left(y^{i}\right)_{i}\right)$. Moreover, they show that it is not possible for a decentralized allocation mechanism to use a message of smaller dimension, such as the price vector alone, and still achieve Pareto optimal allocations for all classical pure exchange environments. The Hurwicz (1977) and Mount and Reiter (1974) model is nonstochastic, but the reasoning behind the result can be illustrated using the two-person, two-commodity example of the previous section. Let $\bar{M}$ be an arbitrary set of equilibrium messages, let $Y=\left\{\left(y^{1}, y^{2}\right) \in \mathbb{R}^{2} \times \mathbb{R}^{2}: y^{1}+y^{2}=0\right\}$, and let $h: \bar{M} \rightarrow Y$ be an arbitrary outcome function. Fix the endowments at $e^{1}=e^{2}=(3,3)$ as before. A (nonstochastic) exchange environment is then specified by a pair of utility functions $\left(u^{1}, u^{2}\right) \in U^{2}$. An allocation mechanism consists of a correspondence $\mu: U^{2} \rightarrow \rightarrow$ $\bar{M}$, called the equilibrium message correspondence, together with the outcome function $h: \bar{M} \rightarrow Y$. The correspondence $\mu$ associates with each $\left(u^{1}, u^{2}\right)$ a set $\mu\left(u^{1}, u^{2}\right)$ of equilibrium messages, and the function $h$ associates with each $m \in \mu\left(u^{1}, u^{2}\right)$ a net trade outcome $\left(y^{1}, y^{2}\right)=h(m)$. In order to represent the competitive mechanism in this way, we require $h\left(\mu\left(u^{1}, u^{2}\right)\right)$ to be the set of competitive equilibrium trades for each $\left(u^{1}, u^{2}\right)$. Obviously, each equilibrium message $m \in \mu\left(u^{1}, u^{2}\right)$ must contain enough information about $\left(u^{1}, u^{2}\right)$ to determine the competitive equilibrium net trade. In fact, decentralization requires that messages contain still more information. 
At this level of abstraction, decentralization means simply that the concept of equilibrium can be decomposed into separate equilibrium conditions for each trader. Formally, the allocation mechanism $(\mu, \bar{M}, h)$ is informationally decentralized if there are individual equilibrium message correspondences $\mu^{1}, \mu^{2}: U \rightarrow \rightarrow \bar{M}$ such that for every $\left(u^{1}, u^{2}\right)$,

$$
\mu\left(u^{1}, u^{2}\right)=\mu^{1}\left(u^{1}\right) \cap \mu^{2}\left(u^{2}\right) .
$$

For example, to define the competitive mechanism $\left(\mu_{c}, \bar{M}_{c}, h_{c}\right)$, let $\bar{M}_{c}=M$, let $h_{c}$ be the projection $h_{c}:\left(p, y^{1}, y^{2}\right) \mapsto\left(y^{1}, y^{2}\right)$, and define $\mu_{c}^{i}\left(u^{i}\right)$ to be the set of market signals $\left(p ; y^{1}, y^{2}\right)$ such that $y^{i}$ maximizes $u^{i}\left(e^{i}+z\right)$ subject to $p z=0$. Then use (D) to define $\mu_{c}$ by setting $\mu_{c}\left(u^{1}, u^{2}\right)=\mu_{c}^{1}\left(u^{1}\right) \cap \mu_{c}^{2}\left(u^{2}\right)$. In effect, $\mu_{c}^{i}\left(u^{i}\right)$ is trader $i$ 's offer curve, and the set of competitive equilibrium messages is defined as the intersection of the offer curves.

The decentralization condition (D), as a property of $\mu$, is existential, since it requires the existence of suitable correspondences $\mu^{i}$. However, it is easily seen that the following property is necessary and sufficient for the existence of correspondences $\mu^{1}$ and $\mu^{2}$ satisfying (D):

$$
\mu\left(u_{a}^{1}, u_{a}^{2}\right) \cap \mu\left(u_{b}^{1}, u_{b}^{2}\right)=\mu\left(u_{a}^{1}, u_{b}^{2}\right) \cap \mu\left(u_{b}^{1}, u_{a}^{2}\right)
$$

for every pair of environments $\left(u_{a}^{1}, u_{a}^{2}\right),\left(u_{b}^{1}, u_{b}^{2}\right)$. [See Mount and Reiter (1974, Lemma $5) \cdot]$ 
To see why decentralization requires the equilibrium messages to contain more information than just the equilibrium trades, consider the utility functions from Section 3:

$$
\begin{aligned}
& u_{a}^{1}(x)=2 \ln x_{1}+\ln x_{2}, \\
& u_{b}^{1}(x)=\ln x_{1}+2 \ln x_{2}, \\
& u_{a}^{2}(x)=\ln x_{1}+2 \ln x_{2}, \\
& u_{b}^{2}(x)=2 \ln x_{1}+\ln x_{2} .
\end{aligned}
$$

Note that in the environments $\left(u_{a}^{1}, u_{b}^{2}\right)$ and $\left(u_{b}^{1}, u_{a}^{2}\right)$, there is no trade in equilibrium. Therefore, if the equilibrium messages were just the equilibrium trades, we would have $\mu\left(u_{a}^{1}, u_{b}^{2}\right) \cap \mu\left(u_{b}^{1}, u_{a}^{2}\right)=\{(0,0)\}$, which contradicts $\left(\mathrm{D}^{\prime}\right)$ because the environments $\left(u_{a}^{1}, u_{a}^{2}\right)$ and $\left(u_{b}^{1}, u_{b}^{2}\right)$ have nonzero equilibrium trades.

The reason for this digression into informational decentralization theory is the rather surprising result that a version of $\left(\mathrm{D}^{\prime}\right)$ is necessary for the existence of rational expectations equilibrium. Consider the stochastic exchange environment described in Section 3, but suppose now that the expectations of the uninformed trader are conditioned on the equilibrium message of some allocation mechanism $(\mu, \bar{M}, h)$. To ensure that conditional expectations are well defined, suppose that the equilibrium message correspondence $\mu$ is a single-valued function. Then a fully revealing equilibrium exists if $\mu\left(u_{a}^{1}, u_{a}^{2}\right) \neq \mu\left(u_{b}^{1}, u_{b}^{2}\right)$ (recall that $v^{1}\left(s_{a}\right)=u_{a}^{1}, v^{2}\left(s_{a}\right)=u_{a}^{2}$, etc.), because in that case the equilibrium message reveals the state to trader 2. However, if, as is the case with the equilibrium price, $\mu\left(u_{a}^{1}, u_{a}^{2}\right)=\mu\left(u_{b}^{1}, u_{b}^{2}\right)$, then only a nonrevealing equilibrium is possible, the existence of which requires that $\mu\left(u_{a}^{1}, \pi_{a} u_{a}^{2}+\left(1-\pi_{a}\right) u_{b}^{2}\right)=$ $\mu\left(u_{b}^{1}, \pi_{a} u_{a}^{2}+\left(1-\pi_{a}\right) u_{b}^{2}\right)$, where $\pi_{a}$ denotes the probability of the state $s_{a}$. Hence, the existence of "message-conditional expectations equilibrium" requires that

$$
\mu\left(u_{a}^{1}, u_{a}^{2}\right)=\mu\left(u_{b}^{1}, u_{b}^{2}\right) \Rightarrow \mu\left(u_{a}^{1}, \pi_{a} u_{a}^{2}+\left(1-\pi_{a}\right) u_{b}^{2}\right)=\mu\left(u_{b}^{1}, \pi_{a} u_{a}^{2}+\left(1-\pi_{a}\right) u_{b}^{2}\right) .
$$

Suppose that we further require that equilibrium exist for all values of $\pi_{a}$. If we assume 
that the function $\mu$ is continuous with respect to $\pi_{a}$ and let $\pi_{a} \rightarrow 1$, we obtain the implication

$$
\mu\left(u_{a}^{1}, u_{a}^{2}\right)=\mu\left(u_{b}^{1}, u_{b}^{2}\right) \Rightarrow \mu\left(u_{a}^{1}, u_{a}^{2}\right)=\mu\left(u_{b}^{1}, u_{a}^{2}\right)
$$

Letting $\pi_{a} \rightarrow 0$ strengthens the implication to

$$
\mu\left(u_{a}^{1}, u_{a}^{2}\right)=\mu\left(u_{b}^{1}, u_{b}^{2}\right) \Rightarrow \mu\left(u_{a}^{1}, u_{a}^{2}\right)=\mu\left(u_{b}^{1}, u_{a}^{2}\right)=\mu\left(u_{a}^{1}, u_{b}^{2}\right)
$$

If we further require that equilibrium exist for the stochastic environments obtained by permuting the state-dependent utilities to $v^{2}\left(s_{a}\right)=u_{b}^{2}$ and $v^{2}\left(s_{b}\right)=u_{a}^{2}$, then we add the reverse implication to obtain

$$
\mu\left(u_{a}^{1}, u_{a}^{2}\right)=\mu\left(u_{b}^{1}, u_{b}^{2}\right) \Leftrightarrow \mu\left(u_{a}^{1}, u_{a}^{2}\right)=\mu\left(u_{b}^{1}, u_{a}^{2}\right)=\mu\left(u_{a}^{1}, u_{b}^{2}\right)
$$

which is simply $\left(\mathrm{D}^{\prime}\right)$ for single valued $\mu$. Thus the decentralization condition $\left(D^{\prime}\right)$ is necessary for the existence of a message-conditional expectations equilibrium for every two-state stochastic environment, provided that $\mu$ is single valued and continuous in $\pi_{a}$.

The assumption that $\mu$ is single valued throughout its domain $U^{2}$ is much too restrictive. For the purpose of establishing necessary conditions for the existence of equilibrium, however, we can confine the domain of $\mu$ to the set of log-linear utility pairs. On this domain, the competitive mechanism $\mu_{c}:\left(u^{1}, u^{2}\right) \mapsto\left(p,\left(y^{i}\right)_{i}\right)$ is single valued and also has the required continuity with respect to the utility coefficients. Moreover, any $\mu$ obtained as a continuous function of the competitive message also inherits these properties. That is, if the market variables $\left(p,\left(y^{i}\right)_{i}\right)$ are condensed via any continuous function $f: M_{c} \rightarrow \bar{M}$, the resulting $\mu(\cdot)=f\left(\mu_{c}(\cdot)\right)$ must satisfy $\left(\mathrm{D}^{\prime}\right)$ on log-linear utility pairs as a necessary condition for the general existence of equilibrium with expectations conditioned on the condensed market data. In particular, an REE fails to exist in the example in Section 3 because condensing the competitive message $\left(p,\left(y^{i}\right)_{i}\right)$ to 
the price alone violates $\left(\mathrm{D}^{\prime}\right)$. It is natural to ask whether other condensations might be consistent with $\left(\mathrm{D}^{\prime}\right)$. Unfortunately, Jordan (1977, Theorem 5.4) shows that there is no other continuous condensation, except for the trivial case of the constant function, that satisfies $\left(\mathrm{D}^{\prime}\right)$. However, as will be shown below, the force of this negative result can be lessened by permitting different traders to condition their expectations on different condensations.

Fortunately, the contribution of informational decentralization theory to rational expectations equilibrium is not limited to nonexistence results. It also suggests that in order to obtain general existence theorems, we should extend the concept of rational expectations equilibrium to allow traders to condition their expectations on additional market variables. More formally, suppose that each trader $i$ has a set of market signals $M^{i}$ that are generated by a function $f^{i}: M \rightarrow M^{i}$. Define a generalized rational expectations equilibrium (GREE) as a Borel-measurable function $\left(\tilde{p}(\cdot),\left(\tilde{y}^{i}(\cdot)\right)_{i}\right): S \rightarrow M$ satisfying, for each $i$,

$$
\begin{aligned}
& \tilde{y}^{i}(s) \text { maximizes } E\left\{v^{i} \mid s^{i}, f^{i}\left(\left(\tilde{p}(s),\left(\tilde{y}^{i}(s)\right)_{i}\right)\right)\right\}\left(e^{i}+y^{i}\right) \\
& \text { subject to } \tilde{p}(s) y^{i}=0, \quad \text { for almost every } s .
\end{aligned}
$$

Taking each $f^{i}$ to be the projection $\left(p,\left(y^{i}\right)_{i}\right) \mapsto p$ reduces (4) to (3). Alternatively, suppose that each $f^{i}$ is the identity so that each trader observes the entire competitive message. Then one can show that an FCE is always a GREE. In fact, the same is true if each $f^{i}$ is taken to be the projection $\left(p,\left(y^{j}\right)_{j}\right) \mapsto\left(p, y^{i}\right)$. The proof of this is nearly immediate. Suppose that $\left(\tilde{p}(\cdot),\left(\tilde{y}^{i}(\cdot)\right)_{i}\right)$ is an FCE. We need to show that for each $i$,

$$
\tilde{y}^{i}(s) \quad \text { maximizes } E\left\{v^{i} \mid s^{i}, \tilde{p}(s), \tilde{y}^{i}(s)\right\}\left(e^{i}+y^{i}\right)
$$

subject to $\tilde{p}(s) y^{i}=0, \quad$ for almost every $s$. 
In other words, we need to show that when trader $i$ 's information is reduced from $s$ to $\left(s^{i}, \tilde{p}(s), \tilde{y}^{i}(s)\right)$, the trade $\tilde{y}^{i}(s)$ remains expected utility maximizing. Given any $\left(\bar{s}, \bar{p}, \bar{y}^{i}\right)$, let $\bar{S}=\left\{s \mid s^{i}=\bar{s}^{i}, \quad \tilde{p}(s)=\bar{p}\right.$, and $\left.\tilde{y}^{i}(s)=\bar{y}^{i}\right\}$. Thus, $\bar{S}$ is the set of states that trader $i$ cannot distinguish from one another. The FCE condition (1) states that, for almost every $s \in \bar{S}, \bar{y}^{i}$ maximizes $v^{i}(s)\left(e^{i}+y^{i}\right)$ subject to $\bar{p} y^{i}=0$. It follows immediately that $\bar{y}^{i}$ maximizes any convex combination of the functions $\left\{y^{i} \mapsto v^{i}(s)\left(e^{i}+y^{i}\right): s \in \bar{S}\right\} \quad$ subject to $\bar{p} y^{i}=0$. The conditional expectation in (5) is simply one such convex combination. Thus, the market data $\left(p, y^{i}\right)$ are informationally sufficient to support an FCE as a GREE. It may be interesting to note that this proof is very similar to the usual demonstration that a correlated equilibrium of a game can be supported by using the players' actions as the correlating messages [Aumann (1987)].

The proof indicates that the conditional expectation in (5) can be conditioned on the market data $\left(\tilde{p}(s), \tilde{y}^{i}(s)\right)$ alone so that the private signal $s^{i}$ is unnecessary. However, it is not possible to reduce the data to $\tilde{y}^{i}(s)$ alone, since a trade that is optimal in different states at different prices may fail to maximize the trade-conditional expected utility at any of the respective prices. It is essential to the above proof that the budget constraint $\bar{p} y^{i}=0$ is the same for all $s \in \bar{S}$. In fact, Jordan (1982b, Theorem 2.5) shows that the data $\left(p, y^{i}\right)$ cannot be further condensed, except to a constant, without losing the general existence of equilibrium.

The interpretation of (5) seems troublesome. How can a trader choose a trade to maximize expected utility conditional on the trade itself? This question can be blunted somewhat by adopting $-\sum_{j \neq i} y^{j}$ as a euphemism for $y^{i}$ or by recalling that in auction theory, bidders are assumed to avoid the "winner's curse" by choosing a bid that maximizes their expected payoff conditional on the bid being accepted. However, Beja (1976) shows that when one attempts to formalize an REE as a Bayesian Nash equilibrium, as in auction theory, in which traders choose excess demand functions, the exis- 
tence problem is severe. Thus, while the equilibrium concept defined by (5) completely neutralizes the informational discontinuity, it is not persuasive as a self-contained description of the process by which markets aggregate and communicate information.

One approach to interpreting (5) is to model more explicitly the dynamics of information transmission. A particularly simple model, first suggested by Reiter (1976), is the following. Suppose that traders initially use only their private information so that the market initially moves to a PIE. However, before the PIE trades are executed, traders add to their private information the information revealed by the PIE prices. This will typically change traders' expectations, requiring a new round of trade, and so on. In the example described in Section 2, the PIE prices $\tilde{p}\left(s_{a}\right)=(7 / 12,5 / 12)$ and $\tilde{p}\left(s_{b}\right)=(5 / 12,7 / 12)$ reveal the state to the uninformed trader; thus the second and final iteration is the FCE. When there are more than two possible states, more than two iterations will typically be required to reach a price function $\tilde{p}(\cdot)$ that reveals no further information. In general, the final iteration need not be an FCE.

The two-state example of Section 2 has the interesting property that the final price function, in this case the FCE $\tilde{p}\left(s_{a}\right)=\tilde{p}\left(s_{b}\right)=(1 / 2,1 / 2)$, does not itself reveal the information revealed by earlier prices. Instead, the information is revealed by the trade function $\tilde{y}^{2}(\cdot)$. Jordan (1982c, Theorem 5.7.C) shows that, in general, the information revealed by earlier prices that is decision-relevant to trader $i$ is revealed by the pair $\left(\tilde{p}(\cdot), \tilde{y}^{i}(\cdot)\right)$ at the final iteration. Thus, one can interpret (5) by viewing the pair $\left(\tilde{p}, \tilde{y}^{i}(\cdot)\right)$ as a representation of the decision-relevant information revealed to trader $i$ during the trading process.

A very similar trading process is formulated independently in Kobayashi (1977) in a financial asset market model under the assumptions that (i) traders have constant absolute risk aversion, and (ii) the joint distribution of future asset values and traders' private information is normal. These assumptions guarantee the existence of an REE 
[Grossman $(1976,1978)]$, and Kobayashi proves that the trading process reaches the REE in a number of iterations equal to the number of traders. In Kobayashi's model, the trades at each iteration are actually executed, but the assumption of constant absolute risk aversion prevents the resulting capital gains or losses from having any effect on the process. In both models, it is critical that traders behave myopically and choose their demand as though each iteration were the last.

If traders attempt to anticipate future prices, the informational discontinuity reappears, albeit in a more subtle form [e.g., Border and Jordan (1979), Dubey, Geanakoplos, and Shubik (1987), and Futia (1981)]. For example, consider a finite-period stochastic exchange environment, with only spot markets in each period, in which traders' preferences are not intertemporally separable. Because future consumption affects preferences for current consumption, a trader will attempt to anticipate future prices when choosing current demand. Suppose that traders condition their expectations on private information and past prices. Then current prices influence future information and thus influence future prices. Traders' rational expectations of future prices, conditional on current information, influence current demands, which determine current prices. Because of this feedback, the discontinuous relation between prices and information can again prevent the existence of equilibrium.

\section{Efficiency Properties of REE}

One reason for dissatisfaction with fully revealing rational expectations equilibria and the microeconomic models that generate them is that, realistically, such equilibria are too good to be true. The situation described in Sections 2 and 3 contradicts our economic intuition in a significant way. We do not believe that prices can transmit all information of interest to economic agents because information may be extremely complicated, with different types of information being most relevant for different trades. No 
finite number of (even continuously variable) prices for commodities that are transacted in markets can completely capture this complex information.

If all useful information were to be carried by equilibrium prices, the equilibrium would be at least informationally efficient and, in the absence of other potential market distortions, one could perhaps expect the resulting allocation to be optimal in a wider sense. However, full Pareto optimality cannot be expected if traders wish to share their risks - insurance markets may be desirable yet precluded by information. Hence, we must restrict efficiency properties by stressing that we only consider efficiency relative to existing markets as well as with respect to the given information structure. With these two important qualifications, fully revealing rational expectations equilibrium allocations are necessarily ex ante Pareto optimal, as observed by Radner (1967).

The situation is rendered more complicated by an important point which was elucidated, by means of an example, in Green (1981). In a general equilibrium model, more information may be undesirable unless complete information is achieved; additional partial information can give rise to Pareto-worse equilibrium allocations because the new information can destroy some previously-feasible opportunities for risk sharing. Essentially, the presence of information can destroy insurance markets, thereby producing inefficiency unless all agents can freely obtain complete information.

A further examination of the optimality of rational expectations appears in Laffont (1985). This article considers the issue of whether partially revealing rational expectations equilibrium allocations satisfy constrained efficiency. Unfortunately, the answer is generally negative. In partially revealing cases, competitive markets do not lead to the transmission of those parts of consumers' information which matter most for achieving Pareto-improving trades. Even if equilibrium prices transmit the maximal amount - in a dimensional sense - of information that can be communicated given the number of commodities present in the economy, the information that is carried by prices could be such 
that it doesn't affect traders' utilities very much. In short, one cannot expect the most important information to be conveyed by prices if prices cannot transmit all information.

The "efficient markets hypothesis" article of Jordan (1983) makes a similar point. Only for three special parametric classes of utility functions - linear, logarithmic, and exponential — do we find informationally efficient rational expectations equilibria. Moreover, these economies obviously constitute "knife-edge" examples; they are not generic in any reasonable sense.

\section{Partially Revealing REE}

In addition to the objection discussed in the previous section - that informationally efficient rational expectations equilibria cannot be expected to arise in most economic situations - fully revealing REE are inconsistent in a more inclusive economic model in which the information is endogenous. Specifically, Beja (1976) argues that strategic players in an REE market game would not gather information, and as a result, information cannot be conveyed by prices. A similar point was made by Grossman and Stiglitz (1976) in a parametric model of a market for a financial asset. They observe that if information can be freely communicated by prices, then no trader would ever pay to gain information. Therefore, REE models with endogenous costly acquisition of information are not consistent.

The standard model of partially revealing equilibrium in financial asset markets is that of Hellwig (1980), which generalizes and extends the model of Grossman and Stiglitz $(1976,1980)$. Traders are assumed to have constant absolute risk aversion, and the joint distribution of private information and future asset values is assumed to be normal. The full revelation of private information is prevented by the device of adding a random noise term to the aggregate supply so that price movements can be caused by either private information or supply shocks. Unfortunately, the existence of the par- 
tially revealing REE appears to depend on the special assumptions of this model. The fact that the original nonexistence example in Green (1977) is created by adding noise to traders' endowments suggests that there is little hope that endowment noise could serve as the basis for a general theory of partially revealing REE.

Progress in analyzing the possibilities for genuinely partially revealing rational expectations equilibria has been disappointing in general. An explicit example of partially revealing rational expectations equilibrium prices is provided in Allen (1981b), but that class of economies suffers from the observation that the combination of price information and any agent's initial private information corresponds to full information. Thus, the rational expectations equilibrium allocations exactly equal the full communication demands evaluated at the resulting market prices. More recently, Ausubel (1990) studies partially revealing rational expectations equilibrium, albeit for a somewhat special economic model.

More generally, results for the partially revealing case all feature some form of approximation, either to exact market clearing or to complete rationality in agents' use of information. To see that slight deviations from precise market clearing greatly simplify the situation, consider our basic model when there are many more (in a dimensional sense) parameters than prices and when (for simplicity) all agents are either fully informed or completely uninformed. Divide the compact parameter set into sets of small diameter and choose a single distinct price for each set in the partition so as to make demand arbitrarily close to zero when the uninformed agents condition on the partition. This forms a rational expectations approximate equilibrium which, by definition, is not fully revealing. A similar trick can be used to construct rational expectations approximate equilibria based on those in Allen (1981a, 1982b) rather than, as outlined above, the finite state case of Radner (1979) or Allen (1984). See Allen (1982a) for details. 
A more complicated approach based on the general idea of "noise" or dispersion is pursued in simultaneous and independent work by Allen (1981c, published as 1985a and 1985b) and by Anderson and Sonnenschein (1981, published in the 1982 Journal of Economic Theory symposium issue). One interpretation of this research is that it illustrates the tradeoff between exact rationality and exact market clearing in the partially revealing context with noise. [Note that these papers take a different approach to the addition of noise than Hellwig (1980) does, in that he adds noise to supplies, whereas Allen (1981c, 1985a, 1985b) and Anderson and Sonnenschein (1981, 1982) use the concept of noise to alter the definitions of rational expectations equilibria in various waysi.e., noisy rationality or noisy market clearing.] Unfortunately, this literature provides only approximations to rational expectations equilibrium.

The big question of formulating a satisfactory and consistent concept of partially revealing rational expectations equilibrium has remained open. An additional desideratum is that these equilibria display the usual properties of the equilibrium price correspondence and, ideally, the same decentralization or implementation features as in the standard model of an exchange economy without asymmetric information.

\section{Conclusion}

Radner's influence on the general equilibrium theory of rational expectations is seminal. Radner $(1967,1968,1972)$ provides the first models of trade among agents with differing private information, the first analysis of the revelation of private information by equilibrium prices, and the first discovery of the informational discontinuity that creates the equilibrium existence problem. Radner (1979) establishes the first result on the generic existence of equilibrium.

Now that subsequent researchers on the existence problem appear to have followed Radner's example of moving on to other topics, it is appropriate to take stock of the re- 
sults. [See Allen (1986) and Radner (1982) for surveys of this literature.] The existence, if not the economic interpretation, of fully revealing equilibrium is well established. In the case of complete markets, Grossman (1981, Theorem 2) shows the general existence of fully revealing equilibrium. In the usual incomplete markets model, other results mentioned above establish the generic existence of fully revealing equilibrium in the lower dimensional case and nearly fully revealing equilibrium in the higher dimensional case. More generally, expanding the market signal to include net trades, as in (5), will always produce a fully revealing equilibrium whenever a full communication equilibrium exists, which requires only the classical assumptions.

The existence of partially revealing equilibrium, in contrast, remains precarious. Results mentioned in Section 6 show that, in various senses of approximation, there exist approximate equilibria with intuitively reasonable revelation properties. With respect to exact equilibria, however, the authors are aware of no existence results that do not rely on very special assumptions on preferences (e.g., constant absolute risk aversion) or the stochastic structure of information (e.g., joint normality). When one reflects on the pervasive use of partially revealing equilibrium in the theory of financial asset markets [e.g., see Black (1986)], the absence of a firm foundation for partially revealing equilibrium is especially disquieting. 


\section{Footnotes}

${ }^{1}$ This is the topology of $C^{\infty}$ uniform convergence on compact subsets of $\mathbb{R}_{++}^{\ell}$, which requires that similar utility functions be uniformly close and have uniformly close mixed partial derivatives of all orders on any closed and bounded subset of strictly positive commodity bundles $x \in \mathbb{R}_{++}^{\ell}$. However, for all of the results described in this paper except those based on Allen (1982b) and Jordan (1982a), we equally could have used utilities that are required only to be twice continuously differentiable; in that case, the subset $U$ of $C^{2}\left(\mathbb{R}_{++}^{\ell}, \mathbb{R}\right)$ would be given the ( $C^{2}$ compact-open) topology of $C^{2}$ uniform convergence on compacta. Similarly, we could use the more complicated $C^{\infty}$ Whitney topology, which imposes very strong similarity requirements "at infinity" and as we approach the boundary of the positive orthant in $\mathbb{R}^{\ell}$ for functions and all of their derivatives.

${ }^{2}$ Roughly, the problem is that there are both a continuum of commodity bundles and a continuum of price values on which to condition expected utility. If the utility of each commodity bundle is viewed as a separate random variable, then - since the conditional expected utility of each bundle is arbitrary on a set of price, values having probability measure zero - for each price, some bundle can be given an arbitrarily high conditional expected utility, making nonsense of conditional expected utility maximization. Kreps (1977) suggests defining conditional expected utility as an integral with respect to a fixed regular conditional probability distribution in order to avoid this problem, but viewing the utility function as a single random variable works just as well. For further details, see the appendix on measurability of demand in Allen (1981a). 


\section{References}

Allen, Beth, 1981a, Generic existence of completely revealing equilibria for economies with uncertainty when prices convey information, Econometrica 49, 1173-1199.

Allen, Beth, 1981b, A class of monotone economies in which rational expectations equilibria exist but prices do not reveal all information, Economics Letters 7, $227-232$.

Allen, Beth, 1981c, The existence of expectations equilibria in a large economy with noisy price observations, Center for Analytic Research in Economics and the Social Sciences Working Paper \#81-01, Department of Economics, University of Pennsylvania (January). Also circulated under the title, The existence of rational expectations equilibria in a large economy with noisy price observations, Discussion Paper No. 78, Sonderforschungsbereich 21, Universität Bonn, West Germany.

Allen, Beth, 1982a, Approximate equilibria in microeconomic rational expectations models, Journal of Economic Theory 26, 244-260.

Allen, Beth, 1982b, Strict rational expectations equilibria with diffuseness, Journal of Economic Theory 27, 20-46.

Allen, Beth, 1984, Equilibria in which prices convey information: The finite case, in: M. Boyer and R. Kihlstrom, eds., Bayesian Models in Economic Theory (Amsterdam: North-Holland), 63-92.

Allen, Beth, 1985a, The existence of rational expectations equilibria in a large economy with noisy price observations, Journal of Mathematical Economics 14, 67-103.

Allen, Beth, 1985b, The existence of fully rational expectations approximate equilibria with noisy price observations, Journal of Economic Theory 37, 213-253.

Allen, Beth, 1986, General equilibrium with rational expectations, Chapter 1 in: W. Hildenbrand and A. Mas-Colell, eds., Contributions to Mathematical Economics in Honor of Gerard Debreu (Amsterdam: North-Holland), 1-23. 
Anderson, Robert M. and Hugo Sonnenschein, 1981, On the existence of rational expectations equilibria, mimeo, Department of Economics, Princeton University (draft dated February 10).

Anderson, Robert M. and Hugo Sonnenschein, 1982, On the existence of rational expectations equilibrium, Journal of Economic Theory 26, 261-278.

Aumann, Robert J., 1987, Correlated equilibrium as an expression of Bayesian rationality, Econometrica 55, 1-18.

Ausubel, Lawrence M., 1990, Partially-revealing rational expectations equilibrium in a competitive economy, Journal of Economic Theory 50, 93-126.

Beja, Abram, 1976, The limited information efficiency of market processes, Research Program in Finance Working Paper No. 43, University of California at Berkeley.

Black, Fischer, 1986, Noise, The Journal of Finance 41, 529-543.

Border, Kim C. and J. S. Jordan, 1979, Expectations equilibrium with expectations conditioned on past data, Journal of Economic Theory 22, 395-406.

Debreu, Gerard, 1972, Smooth preferences, Econometrica 40, 603-615.

Dubey, Pradeep, John Geanakoplos, and Martin Shubik, 1987, The revelation of information in strategic market games: A critique of rational expectations, Journal of Mathematical Economics 16, 105-137.

Futia, Carl A., 1981, Rational expectations in stationary linear models, Econometrica 49, 171-192.

Green, Jerry R., 1973, Information, efficiency and equilibrium, Harvard Institute of Economic Research Discussion Paper No. 284, Harvard University.

Green, Jerry R., 1975, The non-existence of informational equilibria, Harvard Institute of Economic Research Discussion Paper No. 410, Harvard University.

Green, Jerry R., 1977, The non-existence of informational equilibria, Review of Economic Studies 44, 451-463. 
Green, Jerry R., 1981, Value of information with sequential futures markets, Econometrica 49, 335-358.

Grossman, Sanford J., 1976, On the efficiency of competitive stock markets where trades [sic] have diverse information, Journal of Finance 31, 573-585.

Grossman, Sanford J., 1978, Further results on the informational efficiency of competitive stock markets, Journal of Economic Theory 18, 81-101.

Grossman, Sanford J., 1981, An introduction to the theory of rational expectations under asymmetric information, Review of Economic Studies 48, 541-559.

Grossman, Sanford J. and Joseph E. Stiglitz, 1976, Information and competitive price systems, American Economic Review Papers and Proceedings 66, 246-253.

Grossman, Sanford J. and Joseph E. Stiglitz, 1980, On the impossibility of informationally efficient markets, American Economic Review 70, 393-408.

Grunberg, Emile and Franco Modigliani, 1954, The predictability of social events, Journal of Political Economy 62, 465-478.

Handel, Christopher J., 1980, Allocational Efficiency in a Competitive Capital Market (Ph.D. Dissertation, Stanford University).

Hayek, F. A., 1945, The use of knowledge in society, American Economic Review 35, $519-530$.

Hellwig, Martin F., 1980, On the aggregation of information in competitive markets, Journal of Economic Theory 22, 477-498.

Hurwicz, L., 1977, On the dimensional requirements of informationally decentralized Pareto-satisfactory processes, in: K. J. Arrow and L. Hurwicz, eds., Studies in Resource Allocation Processes, (Cambridge: Cambridge University Press).

Jordan, J. S., 1977, Expectations equilibrium and informational efficiency for stochastic environments, Journal of Economic Theory 16, 354-372.

Jordan, J. S., 1982a, The generic existence of rational expectations equilibrium in the higher dimensional case, Journal of Economic Theory 26, 224-243. 
Jordan, J. S., 1982b, Admissible market data structures: A complete characterization, Journal of Economic Theory 28, 19-31.

Jordan, J. S., 1982c, A dynamic model of expectations equilibrium, Journal of Economic Theory 28, 235-254.

Jordan, J. S., 1983, On the efficient markets hypothesis, Econometrica 51, 1325-1344.

Jordan, J. and R. Radner, 1979, The nonexistence of rational expectations equilibrium: A robust example, mimeo, Department of Economics, University of Minnesota.

Jordan, James S. and Roy Radner, 1982, Rational expectations in microeconomic models: An overview, Journal of Economic Theory 26, 201-223.

Kobayashi, T., 1977, A convergence theorem on rational expectations equilibrium with price information, Working Paper No. 79, The Economic Series, Institute for Mathematical Studies in the Social Sciences, Stanford University.

Kreps, David M., 1977, A note on "fulfilled expectations" equilibria, Journal of Economic Theory 14, 32-43.

Laffont, Jean-Jacques, 1985, On the welfare analysis of rational expectations equilibrium with asymmetric information, Econometrica 53, 1-29.

Mount, Kenneth and Stanley Reiter, 1974, The informational size of message spaces, Journal of Economic Theory 8, 161-192.

Muth, John F., 1961, Rational expectations and the theory of price movements, Econometrica 29, 315-335.

Radner, Roy, 1967, Equilibria des marchés à terme et au comptant en cas d'incertitude, Cahiers d'Econométrie (C.N.R.S., Paris) 4, 35-42. [Translated as: Equilibrium of spot and futures markets under uncertainty, Center for Research in Management Science Technical Report No. 24, University of California at Berkeley.]

Radner, Roy, 1968, Competitive equilibrium under uncertainty, Econometrica 36, $31-58$.

Radner, Roy, 1972, Existence of equilibrium of plans, prices, and price expectations in a sequence of markets, Econometrica 40, 289-303. 
Radner, Roy, 1979, Rational expectations equilibrium: Generic existence and the information revealed by prices, Econometrica 47, 665-678.

Radner, Roy, 1982, Equilibrium under uncertainty, in: K. J. Arrow and M. D. Intriligator, eds., The Handbook of Mathematical Economics, Vol. II (Amsterdam: North-Holland), 923-1006.

Reiter, Stanley, 1976, On expectations equilibrium, mimeo, Department of Economics, Northwestern University. 